\title{
River Loire levees hazard studies - CARDigues' model principles and utilization examples on Blois levees
}

\author{
Eduard Durand $^{1, a}$, Jean Maurin ${ }^{2}$, Bastien Bridoux ${ }^{2}$, Arnaud Boulay $^{3}$ and Arnaud Bontemps ${ }^{1}$ \\ ${ }^{1}$ CEREMA, Direction Territoriale Normandie-Centre, Laboratoire Régional de Blois, 11 rue Laplace, 41029 Blois Cedex, France \\ ${ }^{2}$ DREAL Centre-Val de Loire, 5 avenue Buffon, CS96407, 45064 Orléans cedex 2, France \\ ${ }^{3} D D T 45$, faubourg Bannier, 45000 Orléans, France
}

\begin{abstract}
Along the river Loire, in order to have a homogenous method to do specific risk assessment studies, a new model named CARDigues (for Levee Breach Hazard Calculation) was developed in a partnership with DREAL Centre-Val de Loire (owner of levees), Cerema and Irstea. This model enables to approach the probability of failure on every levee sections and to integrate and cross different "stability" parameters such topography and included structures, geology and material geotechnical characteristics, hydraulic loads... and observations of visual inspections or instrumentation results considered as disorders (seepage, burrowing animals, vegetation, pipes, etc.). This model and integrated tool CARDigues enables to check for each levee section, the probability of appearance and rupture of five breaching scenarios initiated by: overflowing, internal erosion, slope instability, external erosion and uplift. It has been recently updated and has been applied on several levee systems by different contractors. The article presents the CARDigues model principles and its recent developments (version V28.00) with examples on river Loire and how it is currently used for a relevant and global levee system diagnosis and assessment. Levee reinforcement or improvement management is also a perspective of applications for this model CARDigues.
\end{abstract}

\section{Introduction \& CARDigues' model concept}

\subsection{Context of hazard studies}

In December 2007, a new French decree related to hydraulic structures (levees and dams) has introduced for owners the necessity to produce a hazard study for each levee system. On the river Loire, 3 major class $\mathrm{A}^{\mathrm{b}}$ state levee systems are present: Orléans, Tours and Authion representing some 240000 inhabitants. Around 40 class $\mathrm{B}^{\mathrm{b}}$ and $\mathrm{C}^{\mathrm{b}}$ levee systems are also presents on the river Loire and its tributaries representing $600 \mathrm{~km}$ of levees.

The aims of levee hazard studies are to point out critical segments of levee protection system and to estimate breach probability under different flood events. For Loire levees a hazard study had to be done on 40 levee systems between 2008 and 2014.

Therefore, a technical committee of Loire levees hazard studies was created with DREAL Centre (owner of levee systems), Irstea and Cerema, two specialized state contractors. Then in 2008, a specific and semiprobabilistic methodology for class $\mathrm{A}^{\mathrm{b}}$ levee breach hazard calculation was established [5] and Cerema developed the dedicated tool named CARDigues. This model which is developed under "Excel" can take simultaneously into account several parameters such as geometry of the levee, geology, geotechnical characteristics of the levee and its foundation but also some parameters coming from technical and visual inspections or extracted from a specific levee database named SIRSDigues or some parameters due to reinforcements or other security barriers coming from management operations.

\subsection{CARDigues' concepts}

In the CARDigues methodology, the levee system is divided in 50 meters long segments (Fig. 1). Each segment is represented by a levee cross-section representing the more critical statement of the levee along this segment.

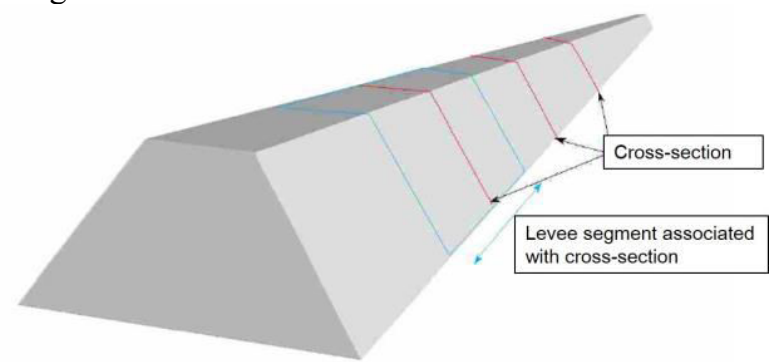

Figure 1. Description of the levee system discretization in representative levee segments (after [10])

\footnotetext{
a Corresponding author: Edouard.durand@cerema.fr

$\mathrm{b}$ levee classes are function of levee height and protected population
} 
Cross-sections were established with Lidar survey and locally field measurements. A high resolution Lidar Flimap was also tested for Orléans levee system. For example, the 3 main river Loire levee systems were divided into 877 (Orléans), 1166 (Tours) and 1593 (Authion) segments.

On each cross-section, breach hazard is calculated for the 5 main failure modes identified on river Loire i.e.: overflowing (s), internal erosion (ei), slope instability(g), external erosion (ee) or scour at the river side levee toe and uplift (sh). These failure modes can be described as levee failure scenarios. Then in CARDigues model, 5 different failure scenarios are distinguished and named by their elementary initiation mechanisms but bring into play more often several elementary mechanisms.

For each flood event of Qi return period, levee breach probability calculations are divided in two parts: the probability of appearance of the initiating phenomena $\mathrm{P}(\mathrm{na})$ and in second time the levee breach probability initiated by this phenomena, $\mathrm{P}(\mathrm{nr})$. Then, the levee breach hazard $\mathrm{P}(\mathrm{n})_{\mathrm{Qi}}$ (or factual probability) initiated by this phenomena (n) is the combination of both former probabilities:

$$
\mathrm{P}(\mathrm{n})_{\mathrm{Qi}}=\mathrm{P}(\mathrm{na}) \times \mathrm{P}(\mathrm{nr})
$$

Two other probabilities are also defined and calculate for each cross section: The "global breach hazard" $\left(\mathrm{P}_{\text {rupture }}\right)_{\mathrm{Qi}}$ for a $\mathrm{Qi}$ return period event, also called the "all modes factual probability" could be obtained by to approaches: by a combination of the opposite factual probabilities (given in equation 2) or considering the maximum of all phenomena factual probabilities (equation $2 b$ ).

$$
\begin{aligned}
&\left(\mathrm{P}_{\text {rupture }}\right)_{\mathrm{Qi}}=[1-((1-\mathrm{P}(\mathrm{s})) \mathrm{x}(1-\mathrm{P}(\mathrm{ei})) \mathrm{x} \\
&(1-\mathrm{P}(\mathrm{ee})) \times(1-\mathrm{P}(\mathrm{g})) \times(1-\mathrm{P}(\mathrm{sh})))
\end{aligned}
$$

Or

$$
\left.\left(\mathrm{P}_{\text {rupture }}\right)_{\mathrm{Qi}}=\operatorname{MAX}[\mathrm{P}(\mathrm{s}) ; \mathrm{P}(\mathrm{ei})) ; \mathrm{P}(\mathrm{ee}) ; \mathrm{P}(\mathrm{g}) ; \mathrm{P}(\mathrm{sh})\right]
$$

And the "annual breach hazard" $\mathrm{P}(\mathrm{n})_{\text {an }}$ also called "annual failure probability". This probability is given by:

$$
\mathrm{P}(\mathrm{n})_{\mathrm{an}}=\sum_{i=50}^{\infty} \mathrm{P}(\mathrm{n})_{\mathrm{Qi}} \times \mathrm{P}(\mathrm{Qi})
$$

where $\mathrm{P}(\mathrm{Qi})$ is the annual probability that the flood event of return period Qi occurs (with $\mathrm{Q}$ representative of an interval $[\mathrm{a}, \mathrm{b}]$ where $\mathrm{Qa}<\mathrm{Qi}<\mathrm{Qb}$ as shown on Fig. 2).

For each cross-section two probabilities are calculated for each flooding situation, for each failure modes and finally for all failure modes.

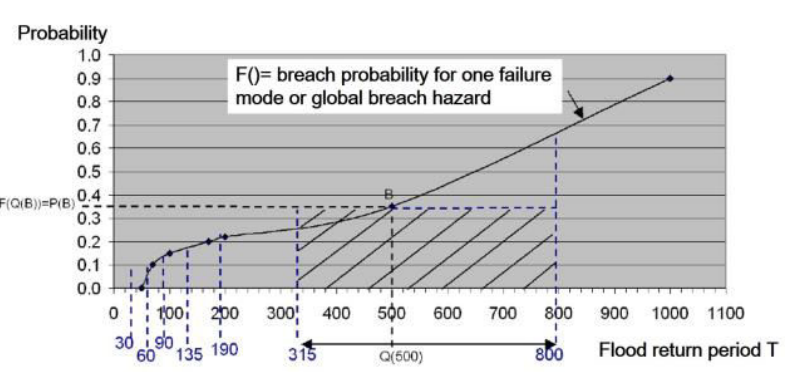

Figure 2. Graphic showing the principle of probabilistic space discretization used in CARDigues (after [6].). For example, the shaded area is affected to the $\mathrm{Q}_{500}$ flood event.

\section{Entrance data of CARDigues}

\subsection{General data}

Each cross-section is localized with a number, its kilometric point $(\mathrm{Pk})$ from the origin of the levee sys-tem. Parish and locality names where stand the cross-section, owner and stakeholder names, number identification from managing database are entered in the tool in order to make the links with former und future studies.

\subsection{Topographic data}

Each cross-section is defined with $\mathrm{X}, \mathrm{Y}$ and $\mathrm{Z}$ coordinates of seven characteristic points (defined on Fig. 3 ). Geotechnical stratigraphic data enable to complete the profile with the positions of the roof of each layers and substratum. The cross-section is then represented by a simplified geometric figure.

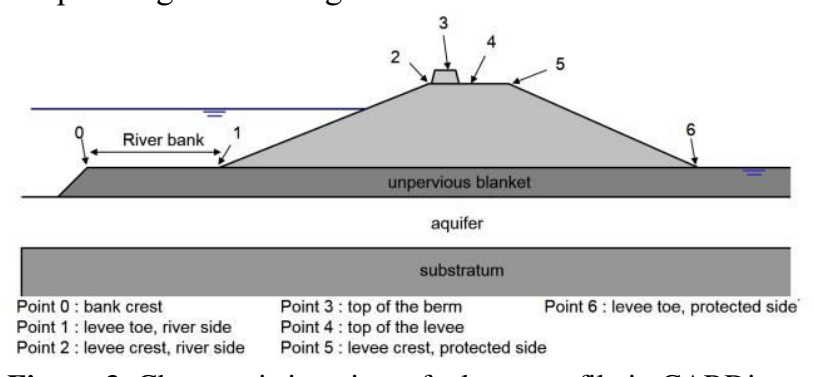

Figure 3. Characteristic points of a levee profile in CARDigues model (courtesy Durand E.)

The point 4 is considered as the top of the levee and defines the levee system crest polyline. Coordinates are set in official reference system: Lambert 93 for $\mathrm{X}$ and $\mathrm{Y}$ and NGF (IGN69) for Z. This topographic data enables to calculate automatically several geometric characteristics such: levee width at the toe and crest, levee height, slopes, riverbank width etc.

\subsection{Hydraulic data}

CARDigues V28.00 can take into account for each cross-section 8 river flood levels given by hydraulic calculations. A hydraulic free level at the protected side of the levee can also be integrated to simulate a former inundation or the presence of water in protected area. 


\subsection{Geotechnical data}

Regarding the global composition of Loire levees all along the river Loire and geotechnical characteristics of materials, a constant "medium levee composition" had been retained. The levee core is then assimilated to a silty sand $\left(c^{\prime}=5 \mathrm{kPa} ; \varphi^{\prime}=30^{\circ}\right.$ and $\left.\gamma_{\mathrm{d}}=18 \mathrm{KN} / \mathrm{m} 3\right)$ and entered in CARDigues model. Levee foundation is described as a 3 geological homogenous strata (Fig. 3). Successively: 1/ a fine soil (silt or clay) with a low permeability; $2 /$ an alluvial coarser pervious strata (sand or coarse sand or gravel) 3/ an impervious substratum.

\subsection{Structural data and disorders}

This kind of information have an influence on probability calculations. They depend on levee utilization, occupation and disorders present on levee such as : presence and type of berm (earthen, masonry wall) on the top of the river or protected side of the levee, embedded structures (house, retaining wall); low points on levee crest; arborescent vegetation and its density (full cover; medium cover or punctual); crossing pipes and its elevation (low, medium, high or its elevation Z); animal burrows (crossing the levee or not); disorders on protected levee slope (obstacles, erosion of grass cover or both); aggravating factors such as scour, obstacles); other aggravating factors of internal erosion.

\subsection{Reinforcement, protection or amelioration data}

The positive factors that increase the levee stability and the levee safety are also integrated in the model. Following elements are taking into account in calculation: presence of a spillway or a segment design for and resistant to overflowing; slope protections on protected side of the levee, cut-off wall; scour protections on river side; other factors that fight against internal erosion.

\subsection{Management data}

The ability of manager to anticipate or repair a deterioration or failure of a levee component can be taken into account. Three cases are distinguished for these secondary factors:

- the operator is able to inspect the levee and to intervene in case of deterioration before the flood event;

- the operator is able to inspect the levee and can intervene in case of deterioration during the flood event; - the operator is not able to inspect the levee and then to intervene in case of deterioration (its notably the case when people safety can't be assumed during exceptional flood event because inspectors must be evacuated);

\section{Breaching processes and failure mechanisms}

CARDigues takes into account the five main failure modes that occurred historically on river Loire levees [2]. They are named by the mechanism that initiate the failure mode and which, combined to each other's, can lead to a breach. Mechanisms are:

\subsection{Overflowing}

The overflowing happens when the river level becomes higher that the elevation of the top of the levee (point 4 on Fig. 3). The flow passes over the crest and erodes the material on the protected side levee slope. This mechanism accelerates itself when slope gets steeper and/or when flow gets concentrated (or perturbed). This scenario often leads to a levee breach. It's slow down with the quality of grass slope revetment, the presence of a protection and the gentleness of the slope.

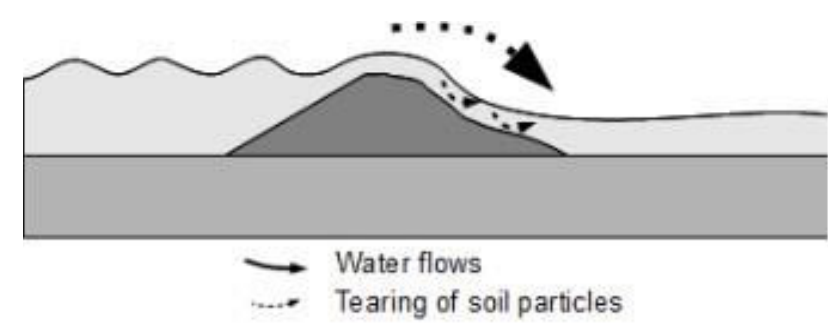

Figure 4. Principle of erosion by overflowing process ([8], Courtesy Y. Deniaud)

\subsection{Internal erosion}

"Internal erosion" is a general appellation to qualify phenomenon where material particles are dragged away by an internal flow. Currently four mechanisms are considered [7]: backward erosion, concentrated erosion, contact erosion and suffusion (Fig. 5).

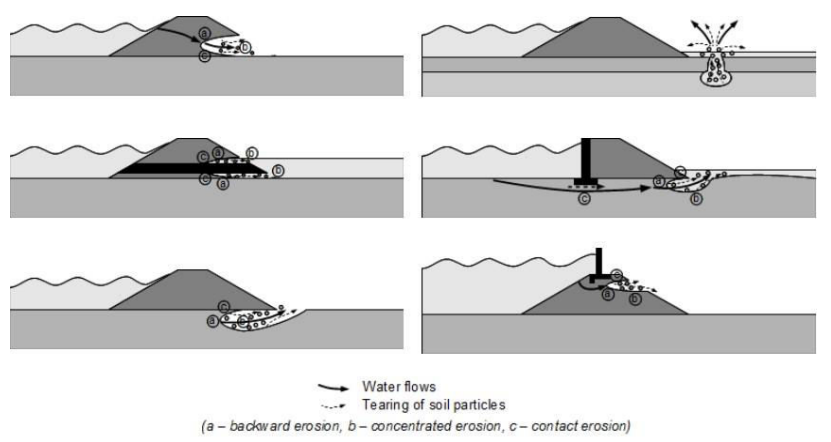

Figure 5. Examples of internal erosion processes and localizations in the levee or its foundation ([8], Courtesy Y. Deniaud)

Two conditions must be fulfilled to initiate internal erosion: the water must flow through the levee core and/or its foundation and particles must have the possibility to be dragged away from material network to the downstream side of the levee.

This phenomenon could accelerate itself when permeability or gradient increase but it can also get stopped if drainage or filtration occurred. For levees, internal erosion is the second cause of breaching process after overflow. It is also often combined with other mechanisms and can constitute the last mechanism that leads to a levee breach. 
In CARDigues methodology, backward erosion (trough or under levee) is considered and its initiation is facilitated by factors such as: animal burrows, tree roots, crossing pipes and the combination of this factors.

\section{3 slope instability}

Slope instabilities are mass instabilities. Horizontal slidings can occur but rotational slidings are mostly observed in earthen levees [8]. This mechanism generally occurs on the protected slope of the levee during flood event but can also occur on the river slope, during drawdown (Fig. 6).
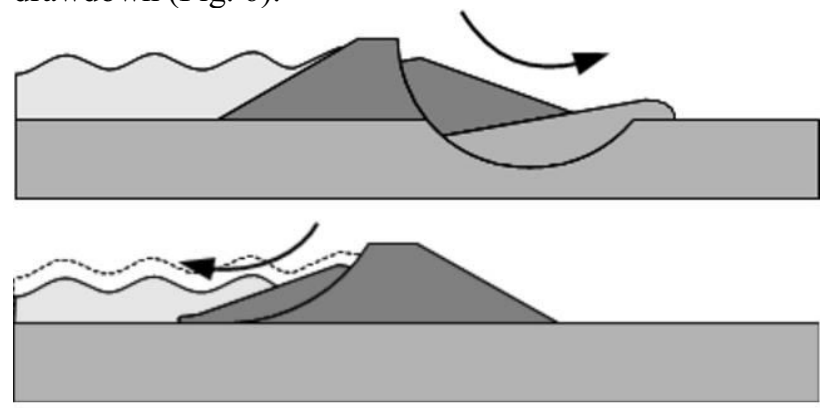

Figure 6. Examples of rotational slope slidings (after [8], Courtesy Y. Deniaud)

Slope sliding mechanism do not lead directly to a levee breach. It can initiate other mechanisms such internal erosion (because of the levee width reduction induced by mass sliding). This scenario is taken into account in CARDigues.

\subsection{External erosion}

In CARDigues methodology, external erosion is scour phenomenon. It occurs when river flow erodes levee toe material or its foundation. Erosion of material on the levee slopes is also external erosion only the first case leads to breach directly in case of overflow (see $\S 4.1$ ). For other cases, external erosion initiates a slope instability and, combined to internal erosion, can lead to the levee breach. This mechanism is affected by aggravating factors (presence of an obstacle at the river toe, pre-existing scour ditch) and can be limited with positive factors (presence of reinforcements at the river levee toe). These factors are taken into account in CARDigues.

\subsection{Uplift}

This phenomenon corresponds to a destabilization process of the protected slope of the levee due to an exceedance of under pressures in the aquifer localized below an impervious layer (Fig. 7).

In case of high hydrostatic pressures in aquifer, cracks can appear in impervious layer (silt or clay). Flow can then appear and backward erosion can be initiated, deformations induced and a decrease of shear strength lead to slope instability. In CARDigues methodology, uplift can't lead to a levee breach by itself but can initiate internal erosion and thereby lead to breach.

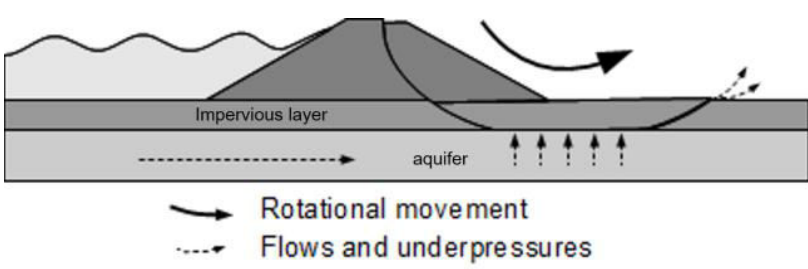

Figure 7. Principle of a slope sliding caused by uplift ([8], Courtesy Y. Deniaud)

\subsection{Other breaching processes}

General instability of levees had never been observed on river Loire levees. Therefore, this mechanism is not treated in CARDigues. Despite the fact it is still frequently observed along the river Loire, the breaching process due to a karstic activity underneath the levee had not been taken into account. The knowledge of this complex phenomenon is currently too poor. That's why some dedicated research pro-jects were recently submitted.

\section{Probability calculations}

\subsection{Hypothesis}

For probabilistic calculations, events that are combined need to be independents. CARDigues model is based on this hypothesis but it's an evidence that levee segments breach probabilities are inter-dependents. Indeed, when a breach occurs on a segment, the neighbour segments are then dragged in the breach and the far from segments would have a minor breach probability induced by hydraulic head reduction provoked by the breach.

Nevertheless, the aim of hazard studies is to estimate the probability of the first breach of the levee system. Thus we considered that probabilities are independents as long as a breach doesn't occur. Therefore, CARDigues model can be used to identify, by relative comparisons, cross-sections were the levee breach failure probabilities are the highest, i.e. cross-sections where breach has the highest chance to occur.

Principles of probability calculations are described in $\S 2.1$ for each failure mode. This complex methodology is based for each failure mode on a logical chart to take into account the most realistic scenarios. Principles of this methodology is described here-under for each of the 5 mains failure modes.

\subsection{Overflowing}

The overflow appearance probability depends on:

- the freeboard, i.e. the difference between considered hydraulic level and levee top elevation (point 4 on Fig. 2 ). It can be positive or negative,

- the presence of a berm on levee crest an its defined efficient height (on flow),

- a height of uncertainties defined to take into account all topographic and hydraulic uncertainties. 
The overflow breach probability, when the phenomenon is occurred depends on the overflowing height. Regarding historical events [11], it is considered that the probability is equal to unit when over-flowing height is greater than $0,20 \mathrm{~m}$. Some specific calculations and probabilities are affected to take in-to account: spillways or overflow resistant segments (where probability is $10^{-3}$ ), berm on protected side of levee crest (case with a breach probability of 1 because of the concentration effect of flow on slope).

Some secondary coefficients $\mathrm{Ci}$ are also used to weight breach probability. It's the case for levee slope on protected side, for width of the levee $(\mathrm{C} 1$ values on Fig. 8 ), for obstacle presence on slope, erosion signs or water height on the protected toe of the levee.

\begin{tabular}{|c|c|}
\hline Width of the levee crest & Coefficient $C_{1}$ \\
\hline $0 m<L<30 m$ & 1 \\
\hline $30 m<L<40 m$ & 0.8 \\
\hline $40 m<L<50 m$ & 0.5 \\
\hline $50 m<L<100 m$ & 0.1 \\
\hline $100 m<L$ & 0.01 \\
\hline
\end{tabular}

Figure 8. Example of overflow breach probability weighting coefficient function of levee width (after [6])

\subsection{Internal erosion}

The internal erosion appearance probability is defined with the average gradient method of Bligh [1] based on the raw ratio $\mathrm{c}=\mathrm{L} / \Delta \mathrm{H}$ (where $\mathrm{L}$ is the levee width at its base and $\Delta \mathrm{H}$ the hydraulic head). A probability is associate in function of intervals of $\mathrm{c}$ as shown in Figure 9.

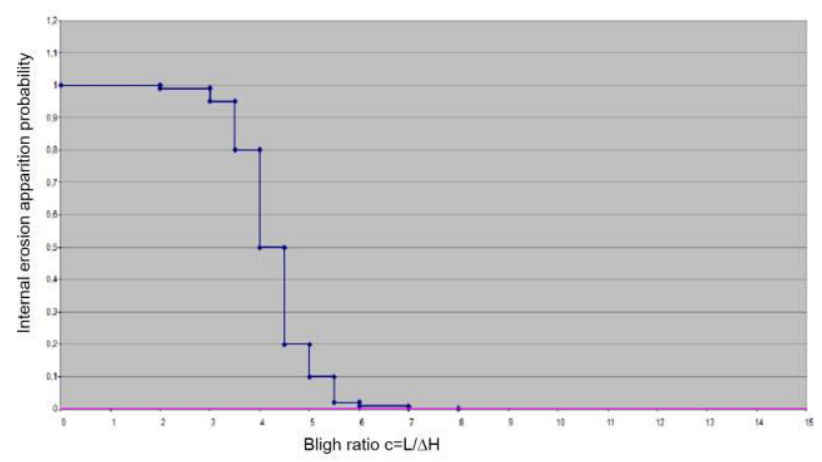

Figure 9. Internal erosion appearance probability function of Bligh ratio (after [6])

This simplify approach is moderated in CARDigues model [9] to take into account typical flood hygrogram, presence of disorders on levees or singularities that modify résistance to internal erosion, specific coefficients (Fig. 10) are applied on levee width L for 3 Loire levees characteristic geotechnical profiles: F1 (unreinforced profile), F2 (profile with reinforcement on river side) and F3 (profile with reinforcement on protected side).

The internal erosion breach probability, when the phenomenon is occurred depends on the presence of drainage and filtering system and secondary on manager surveillance and organization (cf. $\S 2.7$ ).

\begin{tabular}{|l|c|c|c|}
\hline \multirow{2}{*}{ Coefficient applied on raw Bligh ratio } & \multicolumn{3}{|c|}{ coefficients } \\
\cline { 2 - 5 } & $\begin{array}{c}\text { F1: Digue } \\
\text { non } \\
\text { renforcée }\end{array}$ & $\begin{array}{c}\text { F2: Digue } \\
\text { renforcée } \\
\text { cóté Loire }\end{array}$ & $\begin{array}{c}\text { F3: Digue } \\
\text { renforcée } \\
\text { cóté Val }\end{array}$ \\
\hline Profil de base & 1 & 1 & 1 \\
\hline Présence de Maison encastrée Côté Val & 0.95 & 0.95 & 1 \\
\hline Présence de Maison encastrée Cóté Loire & 0.95 & 1 & 0.95 \\
\hline Présence de Maison encastrée des deux cotés & 0.90 & 1 & 1 \\
\hline Présence de terriers non traversant -position haute & 0.69 & 0.67 & 0.73 \\
\hline Présence de terriers non traversant - position moyenne & 0.31 & 0.36 & 0.40 \\
\hline Présence de terriers non traversant - position basse & 0.19 & 0.27 & 0.29 \\
\hline Présence de terriers non traversant en position haute & 0.70 & 0.90 & 0.90 \\
\hline Présence de terriers non traversant en position moyenne & 0.95 & 0.95 & 0.95 \\
\hline Présence de terriers non traversant en position basse & 0.71 & 0.94 & 0.86 \\
\hline Présence de terriers traversant & 0 & 0 & 0 \\
\hline Végétation ligneuse isolée & 0.95 & 0.95 & 0.95 \\
\hline Végétation ligneuse clairsemée & 0.68 & 0.9 & 0.89 \\
\hline Végétation ligneuse généralisée & 0.34 & 0.6 & 0.65 \\
\hline Absence d'horizon argilo-limoneux en couche d'assise & 0.56 & 0.80 & 0.78 \\
\hline Présence d'une paroi étanche & 10000 & 10000 & 10000 \\
\hline
\end{tabular}

Figure 10. Table of coefficients applied on Bligh raw ratio (after [6])

\subsection{Slope instability}

The slope sliding appearance probability is appreciated for each cross section by a factor of safety $\mathrm{F}$ based on limit equilibrium method. F is obtained with parametric calculation at Ultimate Limit States based on CFBR recommendations [4]. F is obtained with Bishop method and is function of levee geometry, material characteristics and hydraulic load. Appearance probabilities are the defined according to $\mathrm{F}$ intervals. The greater is $\mathrm{F}$, the smaller is the probability of slope sliding appearance (cf. Fig. 11).

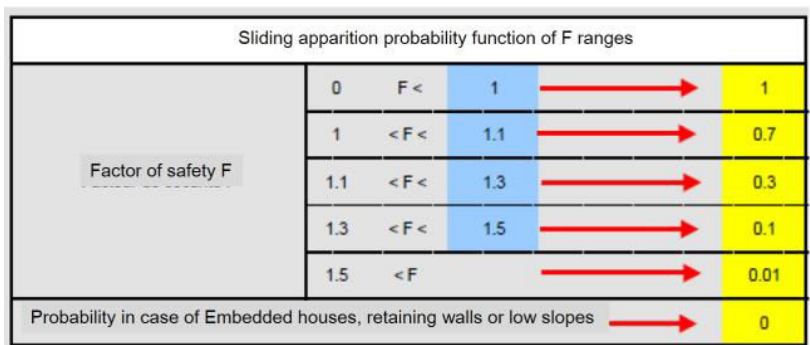

Figure 11. Sliding appearance probability function of factor of safety ranges (after [6])

Some specific reinforcements make the F greater. For example, if a rock berm is present at the river side levee toe, the factor $\mathrm{F}$ is majored by $20 \%$. For following specific cases, the probabilities are fixed to 0 in CARDigues: for embedded houses, for retaining walls, for levee slope smaller than $10^{\circ}$ or for a levee height smaller than $1 \mathrm{~m}$.

A slope sliding provokes a change in levee geometry and therefore increases the internal erosion probability of breach. The slope sliding breach probability $\mathrm{P}(\mathrm{gr})$ is consequently defined in CARDigues with internal erosion hazard that is raised to take into account slope sliding. Two ways of augmentation are offered in the tool: with a coefficient $\mathrm{C}=1,1$ applied on internal erosion hazard $\mathrm{P}(\mathrm{ei})$ or with an over-ranking of probabilities associated to internal erosion appearance probabilities $\mathrm{P}$ (eia) (Fig.12). 


\begin{tabular}{|c|c|c|c|c|}
\hline Qualitative probabilities & El appa & ition proba & $P\left(e_{2}\right)_{1}$ & $P\left(g_{l}\right)$ \\
\hline Nearly zero & - & $P \leq$ & 0,001 & 0,001 \\
\hline insignificant & 0,001 & $<\mathrm{P} \leq$ & 0,01 & 0,01 \\
\hline medium & 0,01 & $<P \leq$ & 0,2 & 0,2 \\
\hline high & 0,2 & $<P \leq$ & 0,8 & 0,8 \\
\hline Very high & 0,8 & $<P \leq$ & 0,99 & 0,99 \\
\hline Nearly certain & 0,99 & $<P$ & -. & 1 \\
\hline
\end{tabular}

Figure 12. Slope sliding breach probabilities based on internal erosion appearance probabilities over-ranking (after [6])

\subsection{External erosion}

In the model, scour is the unique external erosion mechanism taken into account. Indeed, no case of external erosion of river side levee slope had been observed on Loire levees and protected levee slope erosion is treated in overflowing failure mode. It's considered that scour can't lead to breach by itself. It leads to a destabilization of levee toe, causes a slope sliding and finally increases internal erosion process that can lead to a breach.

In CARDigues, the external erosion appearance probability depends on the width of river bank. The less width is the river bank, the more is the probability of (harmful) scour appearance. The model can take into account aggravating factors (existing scour ditch, obstacles and hard point at the levee toe) but also favourable factors (existing reinforcement such rocks berm or sheet piles, soft protections and other scour protections). The external erosion breach probability, when the scour phenomenon is occurred depends on slope sliding breach probability increased with a fixed multiplying coefficient of 4 .

\subsection{Uplift}

The uplift appearance probability is appreciated for each cross section by a factor of safety $F_{h}$ based on USACE method for seepage analysis and control [12]. This factor is a function of several parameters such (Fig. 13) as alluvial and blanket thicknesses and permeability, levee geometry etc.

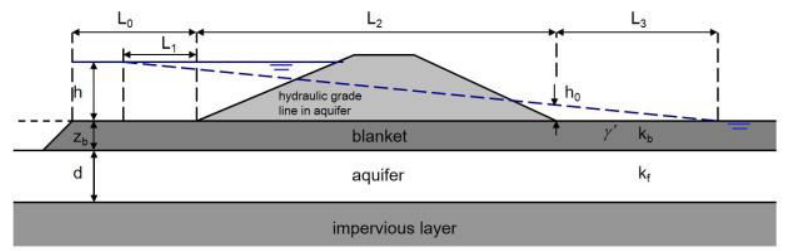

Figure 13. Cross-section and notations used for uplift security factor calculation (after [12])

The factor of safety against uplift at the downstream toe of the levee is given by:

$$
\mathrm{F}_{\mathrm{h}}=\frac{h o}{h c}=\frac{Z_{b d}}{h} \frac{\gamma^{\prime}}{\gamma_{\omega}} \frac{L_{1}+L_{2}+L_{3}}{L_{3}}
$$

where $Z_{b d}(m)$ is the thickness of the downstream blanket, $\mathrm{h}_{\mathrm{c}}(\mathrm{m})$ the critical pressure head, ho the pressure head under the blanket at the downstream toe, $\mathrm{L}_{1}, \mathrm{~L}_{2}, \mathrm{~L}_{3},(\mathrm{~m})$ have to be defined as:

$$
\mathrm{L}_{1}=\sqrt{\frac{k_{f}}{k_{b u}} Z_{b u} d}
$$

where $\mathrm{d}$ is the thickness of aquifer, $\mathrm{k}_{\mathrm{f}}$ is the horizontal permeability of the pervious foundation $(\mathrm{m} / \mathrm{s}), \mathrm{k}_{\mathrm{bu}}$ is the vertical permeability of the upstream blanket $(\mathrm{m} / \mathrm{s}), \mathrm{Z}_{\mathrm{bu}}$ (m) is the thickness of the upstream blanket.

$\mathrm{L}_{2}=$ length of impervious core or levee base (m)

$$
\mathrm{L}_{3}=\sqrt{\frac{k_{f}}{k_{b d}} Z_{b d} d}
$$

where $\mathrm{k}_{\mathrm{bd}}$ is the vertical permeability of the downstream blanket $(\mathrm{m} / \mathrm{s})$.

The uplift appearance probabilities are then de-fined in function of $F_{h}$ ranges. The greater is $F_{h}$ the smaller is

\begin{tabular}{|c|c|c|c|c|}
\hline \multicolumn{5}{|c|}{ Uplift apparition probability function of $\mathrm{Fh}$ ranges } \\
\hline \multirow{6}{*}{$\mathrm{Fh}$} & \multicolumn{3}{|c|}{$\begin{array}{l}\text { no silt OR no alluvial materials } \\
\text { OR no water }\end{array}$} & 0 \\
\hline & 0.00001 & $\mathrm{Fh}<$ & 1.1 & 0.8 \\
\hline & 1.1 & $<\mathrm{Fh}<$ & 1.3 & 0.3 \\
\hline & 1.3 & $<\mathrm{Fh}<$ & 1.5 & 0.1 \\
\hline & 1.5 & $<\mathrm{Fh}<$ & 2 & 0.01 \\
\hline & 2 & $<\mathrm{Fh}$ & & 0.001 \\
\hline
\end{tabular}
appearance probability. If there is no impervious layer at levee foundation, the uplift appearance probability is null.

Figure 14. Uplift appearance probabilities function of ranges of factor of safety (after [6])

Uplift mechanism doesn't lead to breach by itself. When uplift occurs, levee deterioration and cracks in foundation lead to internal erosion in pervious aquifer. The uplift breach probability is then conducted as an internal erosion mechanism with Bligh ratio calculation (without reduction coefficients used for internal erosion). 


\section{Example of results on Blois levee system}

\subsection{Presentation of Blois levee system}

Blois is a city localized between Orléans and Tours with urban areas developed on both banks of river Loire. On the right banks, the flood plain is rapidly limited by small cliffs. On the left bank, the flood plain is wider and the main protected area (in green on Fig. 15) is limited with a $25 \mathrm{~km}$ long levee system installed near the left bank of the Loire from twelfth century up to now. A ring levee also isolates the left bank district of Blois (in yellow in Fig. 15). Blois levees are $\mathrm{B}^{\mathrm{b}}$ (it's up to 1-meterhigh and protect more than 3000 inhabitants) and $C^{\mathrm{b}}$ class levees and therefore required hazard studies.

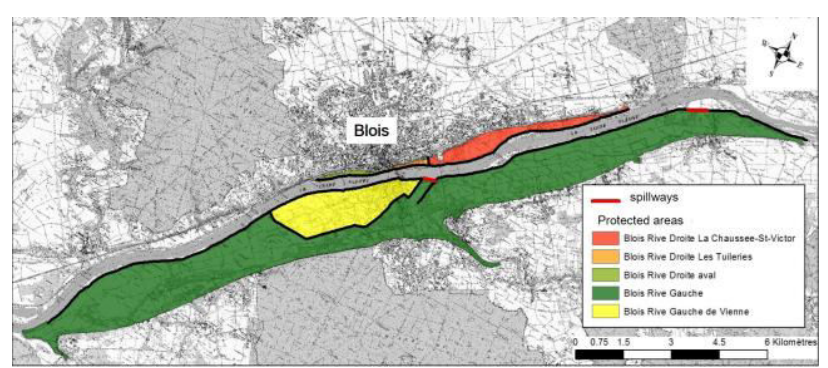

Figure 15. Blois levee systems and its 5 protected areas (after [3])

The main left bank levee is equipped with 2 spillways constructed at the end of nineteenth century of the 3 main Loire flood events in 1846, 1856 and 1856.

\subsection{Blois left ban levee discretization}

For Blois, the class $\mathrm{B}^{\mathrm{b}}$ levee system of the left bank was divided into 517 segments with a spacing of around $50 \mathrm{~m}$.

\subsection{Hydraulic data}

To get hydraulic loads on levee for several flood events, an existing 1D hydraulic model of river Loire was used. Then, levels of Loire for 9 flood events had been determined (from T20 to T1000 where $\mathrm{Ti}$ is the return period of the flood event) and compared to levee longitudinal profile of each levee system. Low points of the levee system were identified and hydraulic entrance data of CARdigues determined.

To completed these 1D data und test several breach scenarios, a 2D hydraulic model of the left protected areas had been established. Heights and speeds of entrance water in flooded areas were thereby calculated and crossed with issues.

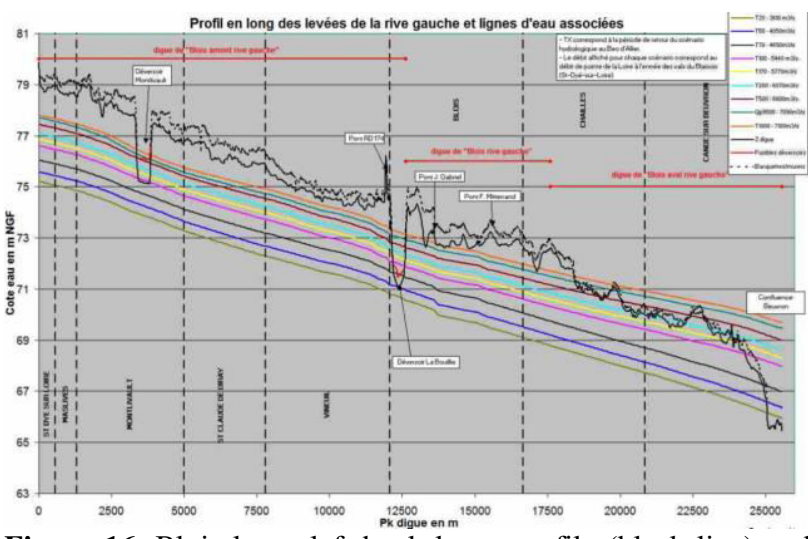

Figure 16. Blois levee left bank levee profile (black line) and the nine flood level taken into account in CARDigues Blois model (after [3])

\subsection{Blois levee cross-section report}

CARDigues has a simplified visualization tool to create levee cross section report (Fig. 17). For each hydraulic situation considered and for each failure mode, all probabilities related to the cross-section are edited (appearance probability, breach probability and hazard). Global hazard for each flood event and annual hazards for each failure mode are also given.

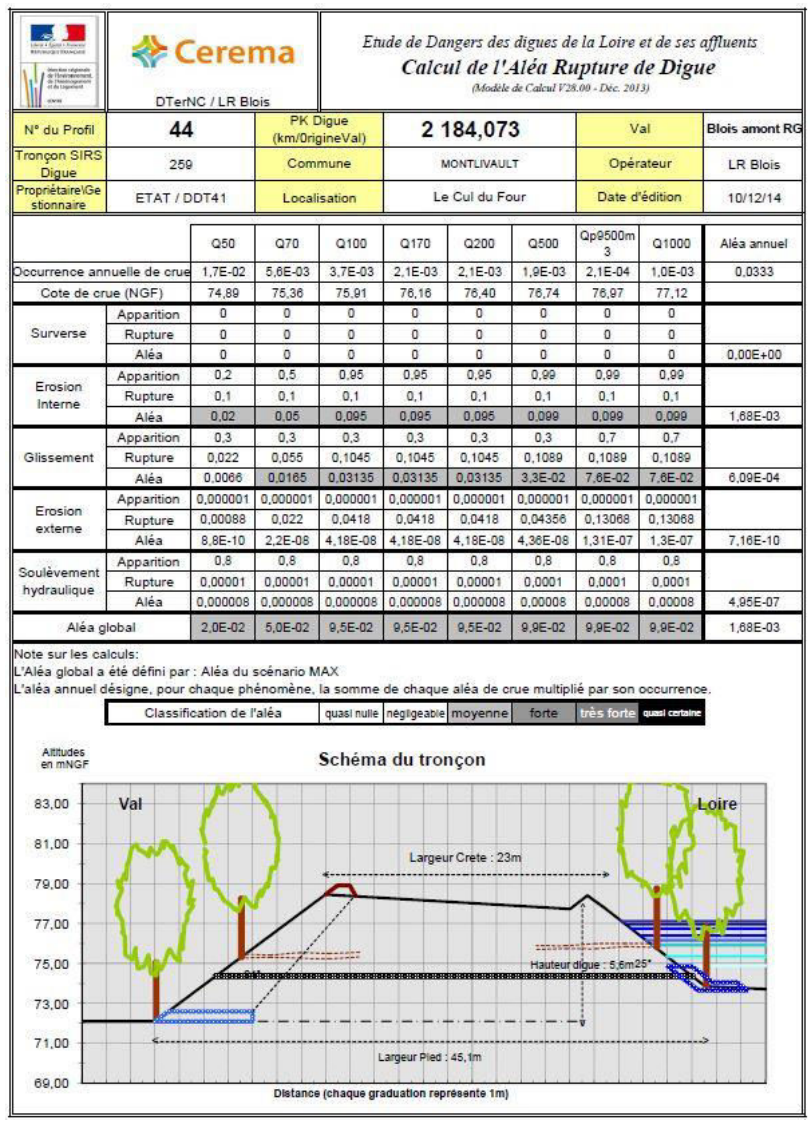

Figure 17. Example of GIS visualization of CARDigues probabilities for the Loire flood T1000 on Blois levees (after [3])

The grey shade hazard classification of the model is also reminded and probabilities are coloured in 
consequences. A simplified scheme is also provided with topographic information, hydraulic levels and disorders (such as trees, burrows, reinforcements, crossing pipes...).

\subsection{GIS presentation of Blois results}

In CARDigues, an exportation sheet enables users to gather main in-formation of different calculation tabs required to edit the results using a GIS software. Combination of exportation data in a GIS tool enables to established results visualization maps. An example of Blois result is shown on the figure 18 where probabilities of each failure mode are sets all along the levee system for each cross section. This kind of maps can be elaborate for each failure mode or each flooding event etc.

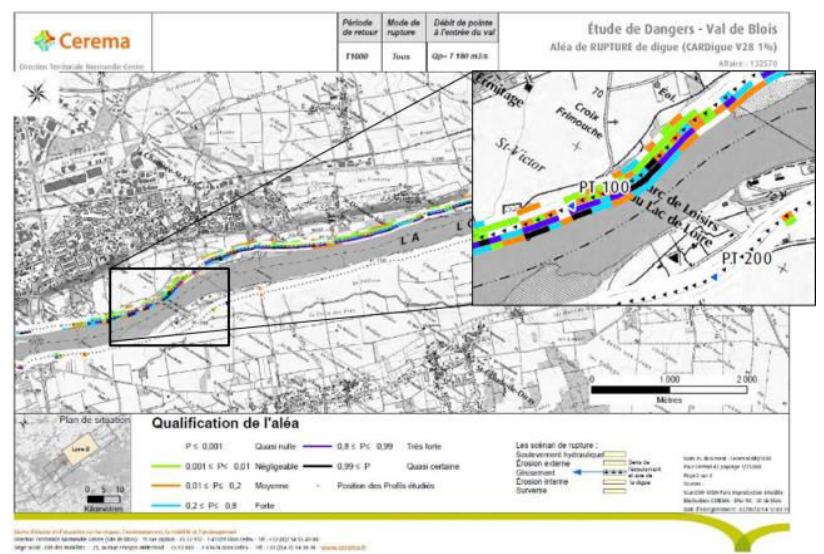

Figure 18. Example of a levee cross-section report edited with CARDigues tool (after [3])

\section{Conclusions and perspectives}

Methodology and CARDigues tool is an innovating tool to realized hazard studies on river Loire levees or to make diagnosis on levee systems. It had been used since 2008 on more than 40 hazard studies and amelioration has been done in 2013 in a new version (V28.00). Nevertheless, other ameliorations could be added in a new version such as:

- improvement of automatic procedure to import data from existing levee databases

- possibility to create new failure scenarios;

- possibility to modify geotechnical parameters of levee core material;

- feasibility of coupling CARDigues with a slope sliding tools to improve slope sliding calculations;

- improve internal erosion parameters that are currently too dependent of crossing pipes

\section{References}

1. Bligh, W. G. (1910). Practical design of irrigation works, Second edition, Constable, Edinburgh.

2. Cemagref (2001). Guide pratique à l'usage des propriétaires et gestionnaires - Surveillance, entretien et diagnostic des digues de protection contre les inondations
3. Cerema (2015). Blois class B and C levees hazard studies. Cerema report $n^{\circ} \mathrm{C} 14 \mathrm{RB} 0060$, may 2015

4. CFBR (2010). Recommandations pour la justification de la stabilité des barrages et digues en remblai. CFBR, version provisoire, juin 2010.

5. Durand, E. (2012) Class A Loire river levees hazard studies. CARDigues methodology report $\left(n^{\circ} 125900\right)$

6. Durand, E. (2015). Blois class B and C levees hazard studies: failure mode model. Simplified fault-trees and CARDigues V28.00 methodology. Cerema report $n^{\circ} \mathrm{C} 14 \mathrm{RB} 0060$

7. ICOLD (2014). Internal Erosion in Existing Dams, Levees and Dikes, and their Foundations, Vol. 1: internal erosion processes and engineering assessment. ICOLD Bulletin $n^{\circ}$ 164, 2014

8. ILH (2013). International Levee Handbook (Ciria, C731, 2013).

9. Maurin, J. (2011). Calcul des digues à l'érosion interne pour un hydrogramme de crue donnée

10. Maurin, J. et al. (2013). Loire river levees hazard studies : failure modes model. Digues maritimes et fluviales de lutte contre les inondations. $2^{\text {ème }}$ Colloque national-Digues2013, Hermes, 2013 Lavoisier, Paris

11. Piney, S. (2011). Retour d'expérience des brèches historiques du val d'Orléans

12. U.S. Army Corps of Engineers (1986). Engineering and design: seepage analysis and control for dam, EM 1110-2-1901. 